OPEN ACCESS

Edited by:

Mojgan Rastegar,

University of Manitoba, Canada

Reviewed by:

Merlin G. Butler,

University of Kansas Medical Center,

United States

Christian P. Schaaf,

Heidelberg University, Germany Marc Lalande,

University of Connecticut Health

Center, United States

*Correspondence:

Janine M. LaSalle jmlasalle@ucdavis.edu

Specialty section:

This article was submitted to Epigenomics and Epigenetics,

a section of the journal

Frontiers in Genetics

Received: 31 October 2020 Accepted: 18 January 2021

Published: 15 February 2021

Citation:

Mendiola AJP and LaSalle JM (2021) Epigenetics in Prader-Willi Syndrome.

Front. Genet. 12:624581.

doi: 10.3389/fgene.2021.624581

\section{Epigenetics in Prader-Willi Syndrome}

\author{
Aron Judd P. Mendiola and Janine M. LaSalle*
}

Department of Medical Microbiology and Immunology, Genome Center, MIND Institute, University of California, Davis, Davis, CA, United States

Prader-Willi Syndrome (PWS) is a rare neurodevelopmental disorder that affects approximately 1 in 20,000 individuals worldwide. Symptom progression in PWS is classically characterized by two nutritional stages. Stage 1 is hypotonia characterized by poor muscle tone that leads to poor feeding behavior causing failure to thrive in early neonatal life. Stage 2 is followed by the development of extreme hyperphagia, also known as insatiable eating and fixation on food that often leads to obesity in early childhood. Other major features of PWS include obsessive-compulsive and hoarding behaviors, intellectual disability, and sleep abnormalities. PWS is genetic disorder mapping to imprinted 15q11.2-q13.3 locus, specifically at the paternally expressed SNORD116 locus of small nucleolar RNAs and noncoding host gene transcripts. SNORD116 is processed into several noncoding components and is hypothesized to orchestrate diurnal changes in metabolism through epigenetics, according to functional studies. Here, we review the current status of epigenetic mechanisms in PWS, with an emphasis on an emerging role for SNORD116 in circadian and sleep phenotypes. We also summarize current ongoing therapeutic strategies, as well as potential implications for more common human metabolic and psychiatric disorders.

Keywords: epigenetic, imprinting, neurodevelopment, metabolic, circadian, diurnal, genetic, obesity

\section{INTRODUCTION}

\section{Clinical Features and Metabolic Phases of PWS}

Prader-Willi Syndrome (PWS) is initially characterized by infantile hypotonia, failure to thrive due to poor suck, small hands and feet, and hypogonadism due to growth hormone deficiencies (Holm et al., 1993; Cassidy et al., 2012; Butler, 2020). During childhood, the development of extreme hyperphagia leads to obesity if not controlled is a major clinical feature of PWS. Other PWS features include obsessive-compulsive disorders, behavioral difficulties, intellectual disability, and sleep abnormalities.

PWS clinical characteristics are classically divided into two nutritional stages; however, it was recently identified that the stages are more complex and can be subdivided into five stages as described in Table 1 (Miller et al., 2011; Butler et al., 2019b). The first stage (phase 0) occurs in utero, characterized by decreased movement in the womb and a low birth weight and size. Generally undiagnosed until birth, infants are assessed for PWS through a series of physical tests that determine the state of reflex and musculature (Holm et al., 1993; Miller et al., 2011; Cassidy et al., 2012). The next stage (phase 1a) of PWS is characterized by hypotonia, which leads to poor feeding and a resultant failure to thrive. Eventually, feeding normalizes entering phase $1 \mathrm{~b}$, but difficulty in feeding remains, and PWS infants often lag in 
TABLE 1 | Clinical characteristics of nutritional phases.

\begin{tabular}{|c|c|c|}
\hline Phase 0 & $\begin{array}{l}\text { Decreased fetal movement and growth } \\
\text { restriction }\end{array}$ & In utero \\
\hline Phase 1a & $\begin{array}{l}\text { Infant becomes hypotonic and can develop } \\
\text { failure to thrive } \\
\text { Infant begins to feed and grows steadily along }\end{array}$ & $\sim 0-9$ months \\
\hline Phase 1b & $\begin{array}{l}\text { a growth curve } \\
\text { Weight increase, without significant change in }\end{array}$ & $\begin{array}{l}\sim 9-25 \text { months } \\
\sim 2-4 \text { years of }\end{array}$ \\
\hline Phase 2a & $\begin{array}{l}\text { appetite or caloric intake } \\
\text { Continuous weight gain with increased food }\end{array}$ & $\begin{array}{l}\text { age } \\
\sim 4-8 \text { years of }\end{array}$ \\
\hline Phase 2b & interest & age \\
\hline Phase 3 & $\begin{array}{l}\text { Development of hyperphagla, increased tood } \\
\text { seeking, and lack of satiety }\end{array}$ & $\sim 8$ years of age \\
\hline Phase 4 & Loss of insatiable appetite and can feel full & Adulthood \\
\hline
\end{tabular}

Miller et al. (2011) and Butler et al. (2019b).

meeting standard developmental milestones. In the more severe cases of PWS, cranial and skeletal features are also apparent (Kindler et al., 2015). Although development is altered and delayed at infancy, patients feeding normalizes resulting in a steady increase in weight. However, stage 2 of nutritional development persists through early childhood, characterized by extreme fixation on food and development of hyperphagia (Holm et al., 1993; Cassidy and Driscoll, 2009; Miller et al., 2011). Stage 2 is divided into two phases in which phase $2 \mathrm{a}$ is an increase in weight that occurs without changes in appetite or feeding followed by phase $2 \mathrm{~b}$, characterized by fixation on food leading to phase 3, hyperphagia. In PWS, hyperphagia is developed at 2 years of age on average, and the severity of hyperphagia varies between children (Miller et al., 2011; Kim et al., 2012; Relkovic and Isles, 2013). Food intake and presence can be controlled by caretakers through proper rationing, reinforcement, and care which is most effective in the early PWS nutritional stages. However, hyperphagia continues to be a life-long struggle that is difficult to control with mitigation efforts. As PWS enters later stages of childhood and into adolescence, some patients enter the final stage (phase 4) and are able to feel full due to increased satiety and decreased behavioral difficulties related to food. It is unclear whether all PWS patients enter phase 4. Severity of clinical features is attributed to the size of deletions and may impact the recovery from hyperphagia (Kim et al., 2012).

Although abnormal sleep patterns are not featured in the nutritional PWS stages, disrupted REM sleep is a severe clinical feature in PWS. Patients with PWS exhibit a disrupted sleep pattern, which is similar to narcolepsy, including increased daytime sleepiness coupled to alterations to REM sleep at night. It is possible that the disrupted REM sleep is directly linked to the other clinical features in PWS. The importance of sleep is critical to the establishment of epigenetic patterns that solidify a diurnal pattern of feeding and metabolism. Once established, this diurnal rhythm is responsible for timing mechanisms regulating development from infancy through adulthood. Disruption of these rhythmic patterns may be causing the delay in development, resulting in the PWS clinical features including hyperphagia, inability to communicate, intellectual disabilities, behavioral difficulties, and obsessive-compulsive tendencies.
Abnormal sleep patterns have been well-established in PWS, however, the molecular outcomes and downstream effects are not well understood. In this article, we will review what is known, delve into promising research findings, as well as discuss some therapeutic strategies for PWS that are either encouraging or controversial.

\section{Molecular Genetics of PWS}

PWS is both a genetic and epigenetic disorder, mapping the imprinted chromosomal domain of 15q11.2-13.3. Common to all cases of PWS is the absence of an expressed paternal copy of the SNORD116 locus. Due to parental imprinting of the locus, outlined in more detail in the next section, loss of SNORD116 can occur through deletion, uniparental disomy, or imprinting error. Most cases of PWS are caused by a large $6 \mathrm{Mb}$ deletion of the entire 15q11.2-q13.3 locus (Holm et al., 1993; Cassidy et al., 2012). Two major large deletion classes include those with breakpoints at BP1 vs. BP2 combined with the downstream BP3 common deletion (Butler, 2020). However, microdeletions of the imprinting control region upstream of SNRPN (Figure 1) also result in loss of expression of SNORD116 due to loss of the promoter. Rare microdeletions that only encompass SNORD116, but not SNRPN or SNORD115, have also been found in patients with PWS (Sahoo et al., 2008; de Smith et al., 2009; Duker et al., 2010). Approximately $60 \%$ of patients have paternal deletions, $36 \%$ are a result of maternal uniparental disomy, $4 \%$ are due to imprinting mutations that lead to a maternal imprinting status, and $<1 \%$ are microdeletions of SNORD116 (Butler et al., 2019a). What is common to all causes of PWS is the absence of SNORD116 expression (Sahoo et al., 2008; Duker et al., 2010; Bieth et al., 2015; Rozhdestvensky et al., 2016).

While these findings establish that the lack of paternally expressed SNORD116 is the likely predominant cause of PWS, there are a greater number of genes in the locus that may contribute to phenotypes of PWS. Both PWS large deletions include MRKN3, MAGEL2, NDN, NPAP1, SNRPN, SNORD repeats, UBE3A, ATP10A, GABRB3, GABRA5, GABRG3, OCA2, and HERC2. Additional genes between the proximal 15q11.2 breakpoints BP1 and BP2 include TUBGCP5, CYFIP1, NIPA1, and NIPA2. Genotype-phenotype investigations between the major molecular subtypes have been somewhat revealing at improving understanding of the genes involved in specific PWS phenotypes. In deletion compared to non-deletion etiologies of PWS, sleep abnormalities were more common (Torrado et al., 2007). Adaptive behavior scores were worse in PWS individuals with $\mathrm{BP} 1-\mathrm{BP} 3$ compared to $\mathrm{BP} 2-\mathrm{BP} 3$ or UPD and obsessive-compulsive behaviors more common in BP1-BP3 compared to UPD (Butler et al., 2004). In the Reiss Screen for maladaptive behaviors, deletion PWS patients showed higher self-injury and stealing scores compared to UPD (Hartley et al., 2005). Together, these studies indicate that gene expression patterns of one or more of these genes may contribute to variable phenotypes within PWS between the molecular subclasses. Below, the imprinted genes in the locus that have been implicated in PWS phenotypes will be discussed in more 
detail, as well as the cluster of biallelically expressed $\mathrm{GABA}_{\mathrm{A}}$ receptor genes (GABRB3, GABRA5, and GABRG3), which are implicated in some of the neuropsychiatric phenotypes that are more severe in the deletion PWS molecular subclass.

SNORD116 is processed through a long noncoding transcript that initiates at the imprinting control region upstream of SNRPN, followed by two repeat clusters of small nucleolar RNAs (snoRNAs SNORD116 and SNORD115) and terminating at the UBE3A antisense transcript (Figure 1; Sutcliffe et al., 1994; Buiting et al., 1995; Runte et al., 2001; Landers et al., 2004; Vitali et al., 2010; Chamberlain, 2013). In humans, SNORD115, but not SNORD116 or UBE3A-ATS, is exclusively expressed in neurons, while Snord116, Snord115, and Ube3a-ats are all neuron-specific transcripts in mouse. SNORD115 and SNORD116 encompass clusters of repeated subunits of sequences encoding a C/D box snoRNAs embedded within intronic regions of the noncoding exons encoding the snoRNA host transcript SNHG14 (Cavaillé et al., 2000; de los Santos et al., 2000; Bortolin-Cavaillé and Cavaillé, 2012; Stanurova et al., 2018). C/D box snoRNAs have known functions in regulating 2-O methylation rRNA modifications by recruiting ribonucleoprotein complexes including fibrillarin, which catalyzes methylation (Dupuis-Sandoval et al., 2015; Bratkovič et al., 2020).

SnoRNAs are processed from introns of the SNORD116 and SNORD115 within the SNHG14 host gene subunits, called as $116 \mathrm{HG}$ and $115 \mathrm{HG}$ (Figure 2; Cavaillé et al., 2000; Leung et al., 2009; Vitali et al., 2010). Unlike other C/D box snoRNAs, SNORD116 and SNORD115 are classified as "orphan snoRNAs" because their targets and functions are unknown (Bratkovič et al., 2020). Previous studies have shown that SNORD116 localizes in the nucleolus and may participate in splicing and RNA modifications (Bazeley et al., 2008; Leung et al., 2009). In contrast, $116 \mathrm{HG}$ and $115 \mathrm{HG}$ localize in the form of RNA "clouds" at the site of their own transcription in the nucleus (Figure 2), and dynamically regulate many additional genes across the genome (Powell et al., 2013; Coulson et al., 2018b). SNORD115 is also shown to be involved in the alternative splicing specifically of the serotonin receptor 5-HT2C mRNA (Bazeley et al., 2008; Raabe et al., 2019). Although, both loci are potentially implicated in PWS, microdeletion of only the
SNORD115 cluster does not lead to the PWS phenotype in humans (Runte et al., 2005). To date, the precise mechanisms of how Snord116 functions are critical for neurodevelopment remain elusive, however, advancements in sequencing technology have provided new insights and will be covered in more detail in the section below. In addition to SNORD116, other genes in the 15q11.2-13.3 locus, including NECDIN, MAGEL2, and a cluster of GABA receptor genes are implicated in the phenotypes observed in most cases of PWS.

NECDIN $(N D N)$ is an imprinted gene that is paternally expressed and encodes for the protein NECDIN, which belongs to the melanoma antigen-encoding gene (MAGE) family of proteins that are enriched in differentiated cells. NDN is one of several protein coding genes deleted from the large $6 \mathrm{Mb}$ chromosomal deletion observed in PWS patients and is implicated in neuronal maturation (Ren et al., 2003). Other than its role in cellular differentiation and neuronal maturation, $N D N$ is also involved in neurite and axonal growth, arborization, migration, and fasciculation, which are important for normal neurological signaling and development (MacDonald and Wevrick, 1997; Kuwajima et al., 2006; Davies et al., 2008; Miller et al., 2009; Bervini and Herzog, 2013). Mouse models of Ndn deficiency have been instrumental for studying abnormal brain development and cognitive impairments in PWS. However, studies using $N d n$ deficient mice did not exhibit any morphological differences in brain development, but led to respiratory failure causing apneas and irregular breathing patterns that are caused by increased activity in serotonin transporter (SERT/slc6a4; Matarazzo et al., 2017). Furthermore, Ndn knockout mice exhibit a higher pain threshold due to a decrease in nerve growth factor sensory neurons (Kuwako et al., 2005). Respiratory failure and higher pain thresholds are also observed in patients with PWS (Rittinger, 2001; Butler et al., 2002; Angulo et al., 2015). Specifically, irregularities in breathing may be a large proponent to sleep abnormalities in PWS.

MAGEL2 is another imprinted gene, that is, paternally expressed and encodes for the protein MAGEL2 that belongs to the MAGE family of proteins. Truncated MAGEL2 mutations cause PWS-like phenotypes observed in patients (Schaaf et al., 2013; Fountain and Schaaf, 2016), but these

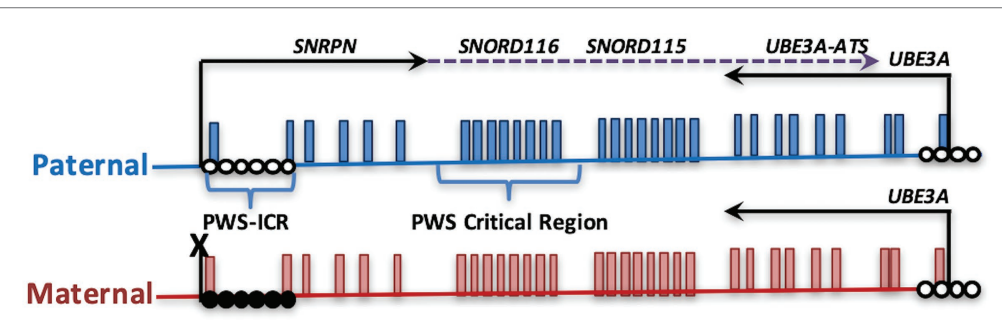

FIGURE 1 | Parental imprinting in the heart of the Prader-Willi syndrome (PWS) locus. The PWS on human chromosome 15q11.2-q13.3 is shown, depicting transcripts specifically expressed from the paternal (blue) or maternal (red) alleles. PWS patients with rare paternal microdeletions have defined the critical region over SNORD116. DNA methylation (closed circles) on the maternal allele of the PWS imprinting control region (PWS-ICR) silences the expression of SNRPN (solid arrow) and the long noncoding transcript expressed in neurons (dotted arrow) that encompasses repeated snoRNA clusters (including SNORD116 and SNORD115) and the antisense transcript to UBE3A (UBE3A-ATS). UBE3A encodes an E3 ubiquitin ligase protein that regulates protein turnover of multiple cytoplasmic and nuclear factors. Since the paternal UBE3A allele is silenced by the expression of UBE3A-ATS in neurons, deletion or mutation of the maternal copy of UBE3A causes Angelman syndrome. 


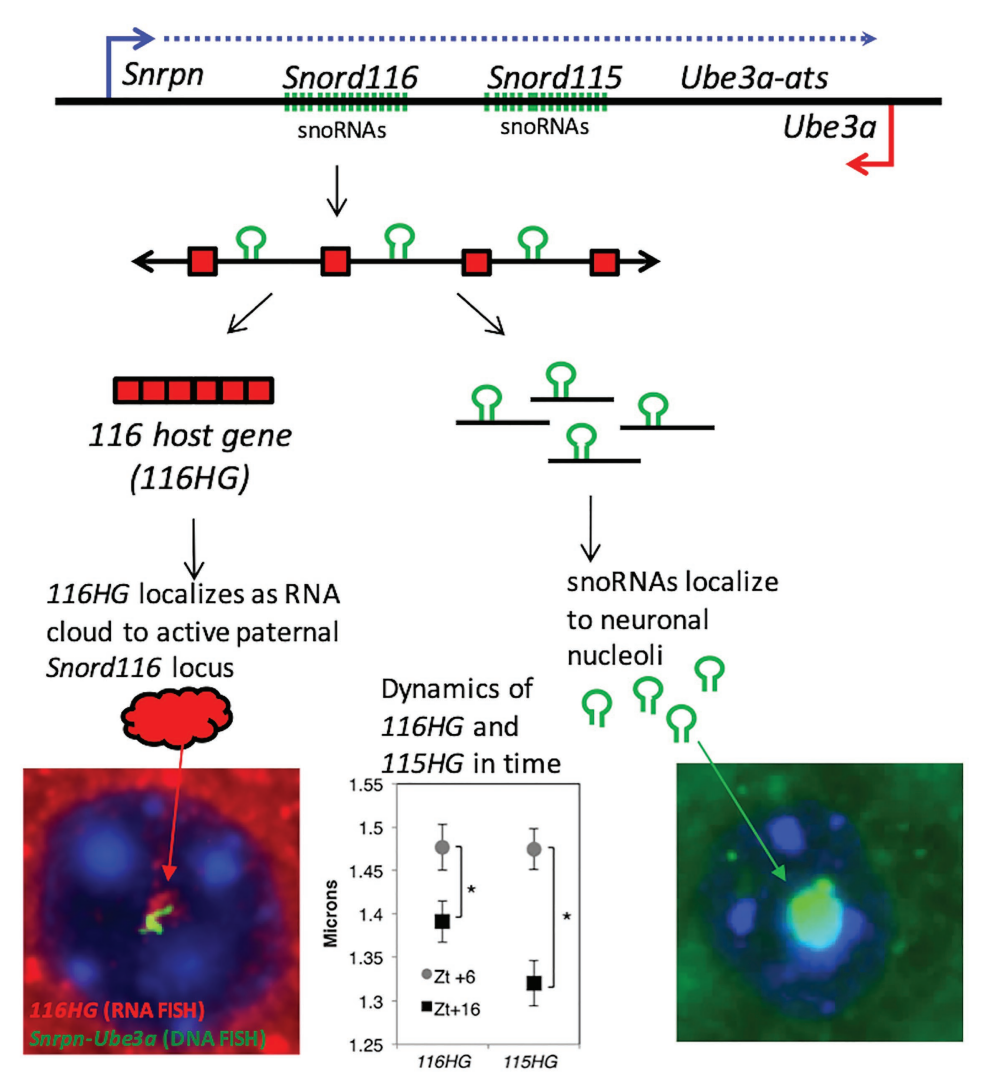

FIGURE 2 | PWS noncoding RNA summary. (Top panel) Individual components of the processed PWS snoRNA-IncRNA region between Snrpn and Ube3a. Within the Snord116 and Snord115 loci are repeated units of snoRNAs (green), IncRNA exons (red boxes), and introns with G-C skew. Processing results in spliced 116HG and $115 \mathrm{HG}$ IncRNAs that localize to their sites of transcription, the snoRNAs that localize to nucleoli, and R-loops that displace histones and promote locus chromatin decondensation. (Bottom left panel) Seen by RNA-FISH, 116HG forms a large RNA cloud (red) localized to the decondensed paternal allele (green) in nuclei (blue), associated with 2,403 genes enriched for metabolic function. 116 HG and 115HG RNA clouds are significantly larger at diurnal time ZT6 (sleep) than ZT16 (wake), corresponding to gene dysregulation in Snord116+/- specifically at ZT6. (Bottom right panel) Processed Snord116 snoRNAs (green) localize to a single nucleolus in mature cortical neurons.

cases have been recently distinguished from PWS in a new classification of Schaaf-Yang syndrome (SYS). SYS shares phenotypic overlap with PWS, but also exhibit distinct behavioral and metabolic phenotypes including autism spectrum disorder (Fountain and Schaaf, 2016). In mouse embryogenesis, Magel2 is highly expressed in non-neuronal (placenta, midgut turbucle, and midgut region) and neuronal tissue types (dorsal root ganglia and peripheral neurons surrounding limb and trunk muscles (Bervini and Herzog, 2013). In adult mouse brain, Magel 2 is highly enriched in hypothalamic regions and extends to the superchiasmic nucleus, specific regions that regulate feeding and circadian rhythms, respectively (Kozlov et al., 2007; Mercer et al., 2009). The prevalence of MAGEL2 in the hypothalamus initially identified it as strong candidate for the hyperphagia phenotype of PWS. However, SYS patients and mouse models with MAGEL2 mutations show a lower prevalence of overeating and obesity. Instead, it was determined that MAGEL2 functions as a ubiquitin transporter that localizes in SCN neurons and acts as a direct regulator of circadian clock proteins through ubiquitination (Mercer et al., 2009; Tacer and Potts, 2017; Vanessa Carias et al., 2020).

The 15q11-q13 PWS region also contains a cluster of three genes encoding subunits of receptors for the neurotransmitter, $\mathrm{GABA}_{\mathrm{A}}$. GABA is the major inhibitory neurotransmitter in the postnatal brain, so loss of these GABA receptors in the large deletion cases of PWS is expected to be involved in some of the phenotypes of PWS. 15q11.2-13.3 genes GABRB3, GABRA5, and GABRG3 encode for $\beta 3, \alpha 5$, and $\gamma 3$ subunits, respectively. $G_{A B A_{A}}$ receptors are assembled into hexameric protein complexes made up of combinations of a1-6, b1-3, g1-3, and other subunits, with $\alpha 5$ containing receptors making up $\sim 5 \%$ of $\mathrm{GABA}_{\mathrm{A}}$ receptors in human brain (Mohamad and Has, 2019). Unlike the imprinted genes in the PWS locus, these $15 q 11.2-13.3 \mathrm{GABA}_{\mathrm{A}}$ receptor genes are biallelically expressed in the brain. However, monoallelic expression and decreased protein expression of each $\mathrm{GABA}_{\mathrm{A}}$ receptor subunits have been observed in autism postmortem brain (Samaco et al., 2005; Hogart et al., 2007). Furthermore, both transcript and protein levels of GABRB3 were not correlated with copy 
number in an analysis of PWS, AS, and 15q11.2-13.3 duplication syndrome postmortem brain (Scoles et al., 2011). A recent study on phenotypes and gene expression patterns in a Gabrb3 deletion mouse model is also consistent with complex gene regulation, as neighboring Oca2 expression was reduced and ocular hypopigmentation observed (Delahanty et al., 2016). Dysregulated gene expression of the $15 \mathrm{q} 11.2-13.3 \mathrm{GABA}_{\mathrm{A}}$ receptors is expected to have consequences for the balance of inhibitory and excitatory signals that regulate sleep, metabolism, and mood in PWS. Recently, it has been shown that levels of GABA metabolites vary between different molecular subclasses of PWS (Lucignani et al., 2004; Rice et al., 2016; Brancaccio et al., 2017). Since there are major targets for therapeutic intervention in multiple neurodevelopmental disorders, understanding their altered expression in PWS is expected to be important for the treatment of other neurodevelopmental disorders (Braat and Kooy, 2015).

\section{EPIGENETIC MECHANISMS IN PWS}

\section{Epigenetic Regulation of the Imprinting Control Region in PWS}

As mentioned in the previous section on molecular genetics, small deletions of the imprinting control region (PWS-ICR) are sufficient to cause PWS when inherited on the paternal allele. Interestingly, the ICR at $15 q 11.2-13.1$ is actually bipartite, because maternal microdeletions of a region called as the AS-ICR are found in rare cases of Angelman syndrome (Buiting et al., 1995; Smith et al., 2011). Subsequent studies in a variety of mammals have demonstrated that the AS-ICR contains alternate $5^{\prime}$ noncoding exon for SNRPN that are uniquely expressed in oocytes, but not sperm or other tissues (Smith et al., 2011; Lewis et al., 2015, 2019). It is the oocytespecific transcription that leads to methylation and transcriptional silencing of the maternal allele specifically on the maternal but not the paternal allele of the PWS-ICR. A more recent study of individuals with AS imprinting mutations have identified a more common haplotype that deletes a binding site for the transcription factor SOX2 (Beygo et al., 2020). Together, these studies have demonstrated that this upstream region, defined as the AS-ICR, is critical for establishing silencing of the maternal allele of the imprinted genes within the PWS locus.

In addition to being characterized by allele-specific DNA methylation, several additional epigenetic marks are differential by parental origin at the PWS-ICR. Specifically, the histone H3 lysine 9 (H3K9) methyltransferase SETDB1 associates with the transcription factor ZNF274 bound to sites within the 5 ' cluster of SNORD116 repeats, resulting in the deposition of maternal-specific H3K9me3 marks (Cruvinel et al., 2014). Knockdown or inhibition of either SETDB1 or ZNF274 was sufficient to induce a low level of SNORD116 transcript expression from the normally silent maternal allele (Cruvinel et al., 2014; Wu et al., 2019; Langouët et al., 2020). Together, these results suggest some promise for possible epigenetic therapies that will be discussed at the end of this review.

\section{Epigenetics and Imprinting in PWS and Related Human Neurodevelopmental Disorders}

In addition to PWS, loss of imprinting is involved in related neurodevelopmental disorders: Angelman (AS), 15q duplication (Dup15q), Kagami-Ogata (KOS14), and Temple (TS14) syndromes (Schanen, 2006; Kagami et al., 2015; Briggs et al., 2016). Unlike the default state of biallelic expression, imprinted genes are selectively silenced on either the maternal or paternal allele by epigenetic differences including DNA methylation and repressive chromatin modifications. Imprinted genes are clustered in discrete chromosomal loci and are regulated by a central imprinting control region (ICR), such as the PWS-ICR, in which methylation is diagnostic for AS, PWS, and Dup15q disorders (Figure 1). Some imprinted genes exhibit tissuespecific or developmental-specific imprinting patterns regulated by long noncoding RNAs. Furthermore, the largest conserved cluster of microRNA (miRNA) in the mammalian genome is found within the KOS14 imprinted locus and is responsible for regulating neuronal maturation and mTOR growth pathways (Winter, 2015). Experimental evidence is emerging for regulatory cross-talk between different imprinted gene loci (Stelzer et al., 2014; Jung and Nolta, 2016; Martinet et al., 2016; Vincent et al., 2016; Lopez et al., 2017), but this emerging "imprinted gene network" hypothesis (Fauque et al., 2010; Haga and Phinney, 2012; Monnier et al., 2013; Ribarska et al., 2014) has been understudied in the context of the developing nervous system.

RNA FISH has shown that $116 H G$ localizes in the nucleus, where it forms an RNA cloud that is absent in Snord116 deletion brain. $116 \mathrm{HG}$ was also found to colocalize with metabolic, circadian, and epigenetic gene loci including Mtor, Clock, Cry1/2, Per1/2/3, Dnmt1/3b, Tet1/2/3, Mecp2, and others at ZT6, the time point with the largest effect of Snord116 deletion on transcription globally (Powell et al., 2013). Snord116's involvement in transcriptional regulation, therefore, prompted an investigation of epigenetic differences that may explain the interaction of Snord116 with diurnal light cycles. Whole genome bisulfite sequencing (WGBS) was performed on cortex samples from wild-type (WT) and PWS mice sacrificed every $3 \mathrm{~h}$ starting from Zt0-Zt16 and showed that Snord116 is involved in regulating a dynamic rhythm of diurnal methylation (Coulson et al., 2018b). Rhythmically methylated CpG dinucleotides were identified $(<1 \%$ of all CpGs) within enhancers and promoters of genes that were undergoing a pattern of reduced methylation during sleep (light hours) in wild-type mouse cortex, a pattern that was lost upon Snord116 deletion. The differentially methylated regions mapped to genes involved in circadian rhythms, metabolism, and epigenetic regulation, similar to the prior genes identified associated with $116 \mathrm{HG}$. Table 2 gives examples of specific genes in each of these categories that were identified by multiple unbiased genomic approaches in both studies. A large portion of genes identified are involved in adding, removing, and 
TABLE 2 | Examples of Snord116 associated and impacted genes and predicted functions.

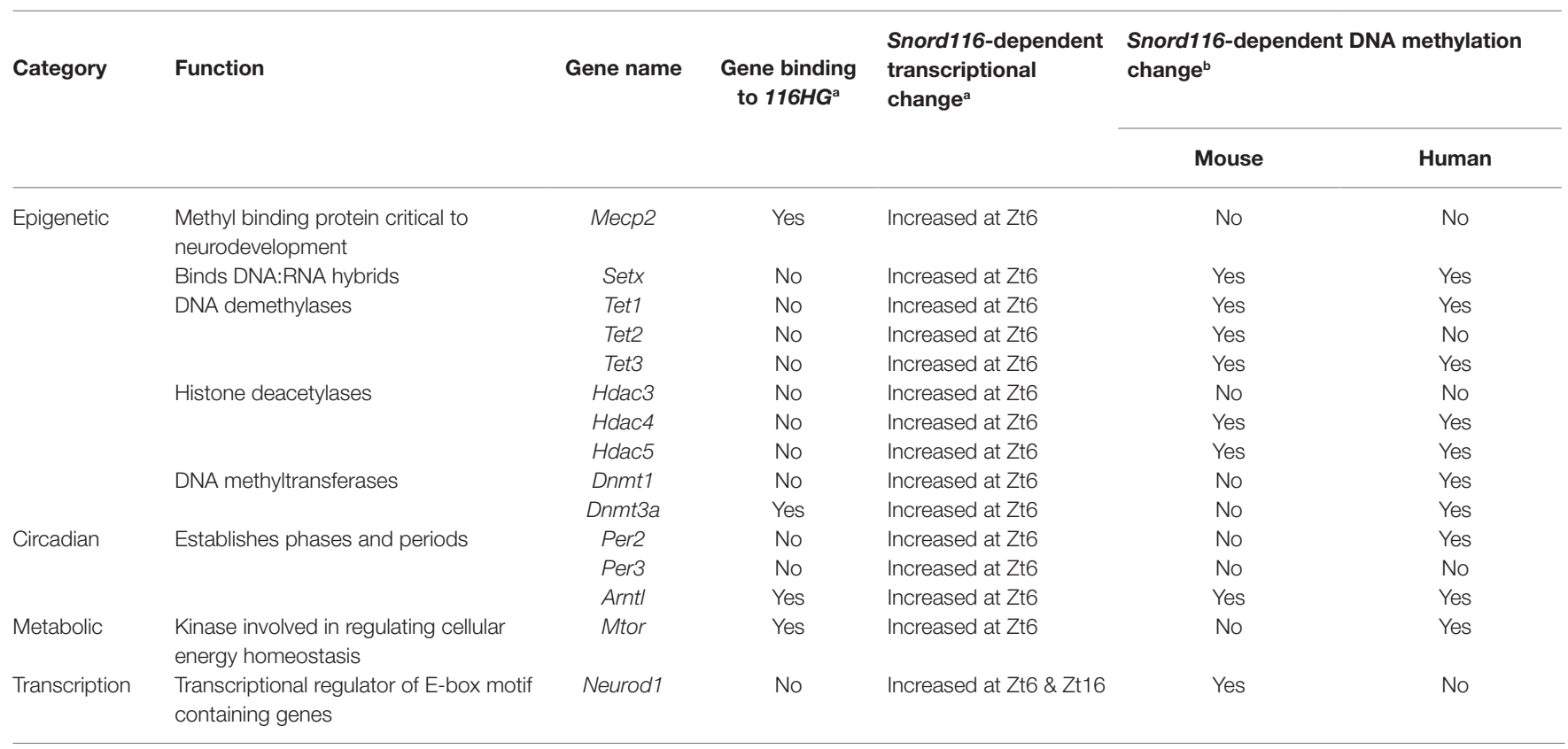

aFull gene lists are included in Powell et al. (2013).

${ }^{b}$ Full gene lists are included in Coulson et al. (2018b).

recognizing DNA methylation while other genes are important transcriptional regulators for development. Further integration of promoter methylation and RNA-seq data revealed that genes being diurnally dysregulated were central to the body weight, behavior, and metabolic phenotypes of PWS (Coulson et al., 2018b).

The Coulson et al. study also demonstrated a molecular connection between the $116 \mathrm{HG}$ and the KOS14 locus, building upon a prior study showing a connection between IPW (part of the $116 \mathrm{HG}$ transcript) and DLK1 regulation at the KOS14/ TS14 locus in human neuronal culture (Stelzer et al., 2014). In this case, DNA FISH was used to examine chromosome decondensation, a measurement of neuronal activation of the paternal allele resulting from histone displacement, at both PWS and TS14 loci in adult mouse brain at six different diurnal time points. Interestingly, the TS14 locus only showed evidence of active chromatin decondensation in Snord116 deletion mouse cortex. Furthermore, chromatin decondensation at the PWS locus did occur in Snord116 deletion, but the timing was shifted from light to dark cycle, similar to the effects observed on DNA methylation. Together, these results suggest that the ancestrally older imprinted TS14/KOS14 locus may become more active as a compensatory mechanism to fill in for loss of Snord116, but this comes at a cost of proper timing of these epigenetic events.

\section{Epigenetics and Imprinting of Mammalian Imprinted Loci and the Emerging Importance in Circadian Rhythmicity and Sleep}

Daily and seasonal cycles of light, temperature, and feeding govern energy and activity of organisms from all branches of life.
These environmental and metabolic inputs play an important role in the synchronization of the core circadian clock with the rhythmic patterns of many physiological and behavioral processes in peripheral tissues (Wright et al., 2013; Legates et al., 2014; Mukherji et al., 2015; Blasiak et al., 2017). The genetically encoded circadian cycle and the environmentally regulated diurnal/nocturnal cycle are integrated by a complex regulatory feedback network, which acts at the chromatin, transcriptional, and translational levels to coordinate biological and environmental rhythms (Koike et al., 2012; Papazyan et al., 2016; Takahashi, 2017). In mammals, the core circadian clock resides in the suprachiasmatic nucleus of the hypothalamus; however, almost half of all transcripts, both protein-coding and non-coding, exhibit diurnal rhythms in one or more peripheral tissues (Yan et al., 2008; Zhang R. et al., 2014). While most studies on circadian biology focus on the suprachiasmatic nucleus, investigations into diurnal rhythms of cerebral cortex are relevant to the cognitive deficits in PWS and to energy expenditure. For instance, circadian and metabolic genes showed light-cycle-specific dysregulation in the Snord116del mouse model, corresponding to cyclical dynamics of Snord116 expression (Powell et al., 2013). Rhythmic epigenetic dynamics within the cerebral cortex are less well characterized; however, increasing evidence indicates a role for DNA methylation in these rhythms. Approximately $6 \%$ $(25,476)$ of $\mathrm{CpG}$ sites assayed by $450 \mathrm{k}$ array are dynamically regulated throughout diurnal and seasonal cycles in human cortex (Lim et al., 2017). This epigenetic plasticity plays an important role in circadian entrainment and the resiliency of the circadian clock to changes in the diurnal environment (Stevenson and Prendergast, 2013; Azzi et al., 2014; Lim et al., 2014). 
The 14q32.2 imprinted locus bears striking similarity to the PWS locus, as it encodes the only other repetitive cluster of snoRNAs in the mammalian genome (SNORD113 and SNORD114), which are maternally expressed and exhibit allele-specific chromatin decondensation in neurons, similar to SNORD116 and SNORD115 (Cavaillé et al., 2002; Tierling et al., 2006; Leung et al., 2009). TS and KOS are reciprocally imprinted disorders, with TS caused by maternal uniparental disomy 14 [UPD(14)mat], and KOS caused by paternal uniparental disomy 14 [UPD(14)pat]. Loss of paternal gene expression at this locus in TS, results in aberrantly high expression of maternal non-coding RNAs, including SNORD113 and SNORD114, whereas KOS results from the loss of maternally expressed, non-coding RNAs and the upregulation of paternally expressed DLK1. Interestingly, TS phenocopies PWS suggesting that these two imprinted loci may perform similar functions and share common pathways (Temple et al., 1991; Hosoki et al., 2009; Kagami et al., 2015). The loss of Snord116 in PWS increases gene expression in the TS locus, indicating that the two loci may interact through a cross-regulatory network. In support of this hypothesis, IPW from the PWS locus has been shown to regulate the TS locus in an induced pluripotent stem cell line of PWS (Stelzer et al., 2014). Though both PWS and TS loci show circadian oscillations, the mechanism of this regulation and the impact of circadian rhythms on their cross-regulation suggests that a balance between the two loci is critical for sleep and metabolism (Labialle et al., 2008a,b; Powell et al., 2013).

Most imprinted loci, such as IGF2, PEG1/MEST, and $I G R 2 R$, are imprinted in marsupials as well as eutherian (placental) mammals (Figure 3). In contrast, Snrpn and Ube $3 a$ are not imprinted in marsupials and are on distinct chromosomes (Rapkins et al., 2006). Interestingly, the ancestral eutherian mammal tenrec (Echinops telfairi) lacks the Snord116 and Snord115 genes and Snrpn and Ube3a are on separate chromosomes (Rapkins et al., 2006; Yasui et al., 2011; Zhang Y. J. et al., 2014). Humans (and chimps) have 22 SNORD116 and 44 SNORD115 copies, while mouse has 27 detectable Snord116 and 130 Snord115 copies. Potentially relevant for the PWS phenotype, tenrecs have a unique metabolic and sleep structure among mammals adapted to long periods of reduced activity and body temperature called torpor (Lovegrove and Génin, 2008; Lovegrove et al., 2014a,b). Non-REM sleep and periods of torpor are thought to be ancestrally adaptive to conserve energy and escape predation. Eutherian mammals have distinct adaptations for daily sleep and activity patterns based on diet, body size, and brain size (Siegel, 2005; Gerhart-Hines and Lazar, 2015).

Unlike the PWS/AS locus, the chromosomal arrangement of the SNORD113/SNORD114 cluster at the KOS/TS locus is similar in monotremes, marsupials, and placental mammals, and the miRNAs at this cluster are evolutionarily stable (Zhang Y. J. et al., 2014). Both imprinted snoRNA loci exhibit neuron-specific chromatin decondensation (Leung et al., 2009) and also show evidence for diurnally expressed transcripts, many of which are also dysregulated in Snord116del mice (Powell et al., 2013; Coulson et al., 2018b). Interestingly, circadian rhythmicity of the Dlk1/Dio3 (Labialle et al., 2008a,b) and Magel2 (Kozlov et al., 2007; Devos et al., 2011; Tennese and Wevrick, 2011) loci and cross-regulation between PWS/AS and DLK1 loci have been described previously (Stelzer et al., 2014) but are poorly understood at a mechanistic level.

Despite its function being fully known, loss of Snord116 in PWS mouse models has been demonstrated to dysregulate sleep, feeding, and temperature cycles (Lassi et al., 2016a,b). These studies have demonstrated the importance of hypothalamic Snord116 expression on temporally regulated behavior. Interestingly, Snord116 deficient mice exhibited disrupted feeding cues induced by erratic behavior due to

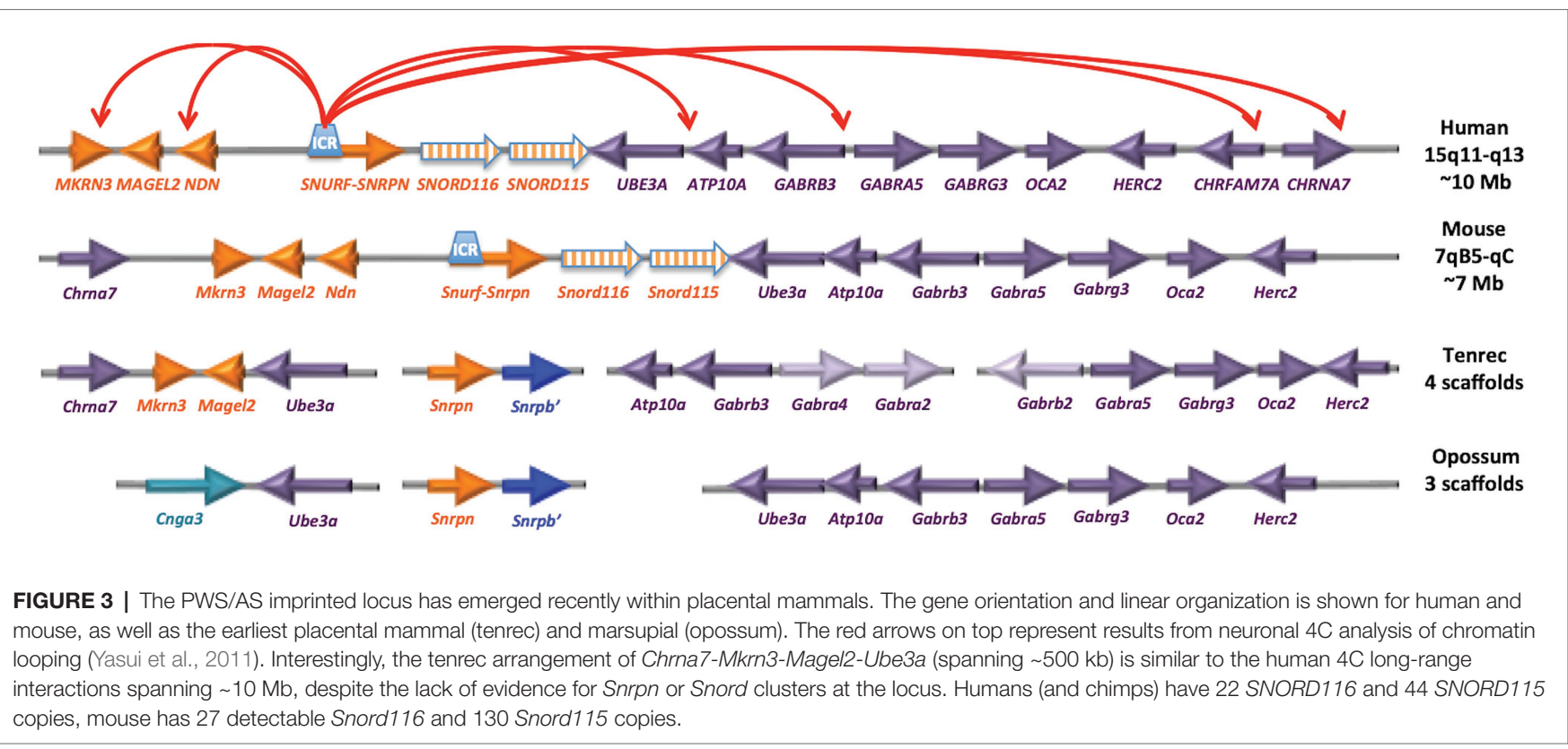


increased activity prompted by foraging. Reminiscent of humans with PWS, Snord116 deficient mice exhibited a strong fixation on food and high food intake irrespective of weight gain (Lassi et al., 2016a). Furthermore, Snord116 deficient mice also exhibited a prolonged REM phase that was uncoupled with normal circadian patterning (Lassi et al., 2016b). Together, these studies have demonstrated the importance of Snord116 on temporally regulated behaviors including sleep, feeding, foraging, and temperature regulation that are consistent with the recent evolutionary selection of the imprinted PWS locus in mammalian-specific diurnal cycles.

Multiple studies have also explored the role of Snord116 in hypothalamic regulation of hormones linked to diurnal behaviors. Orexin neurons in the hypothalamus facilitate sleepwake cycles by regulating hormones that promote wakefulness (noradrenaline, histamine, and acetylcholine) and rest [melanineconcentrating hormone (MCH); Pace et al., 2020]. Loss of orexin neurons are widely implicated in dysregulated sleep in patients with narcolepsy and has been observed in patients with PWS as well (Vgontzas et al., 1996; Chemelli et al., 1999; Mignot et al., 2002; Omokawa et al., 2016). However, it was not until recently that loss of Snord116 was demonstrated to decrease orexin neuron levels in the lateral hypothalamus without altering levels of $\mathrm{MCH}$ and $\mathrm{MCH}$ neurons in mice (Pace et al., 2020). A decrease in orexin neurons may facilitate the prolonged REM sleep characteristic of PWS due to the imbalance in orexin/ $\mathrm{MCH}$ ratio with a higher $\mathrm{MCH}$ concentration during wake cycles promoting more rest (Pace et al., 2020). This phenomenon is not unique to Snord116 deletion mice, however, as this orexin/ $\mathrm{MCH}$ imbalance was also observed in Magel2 deficient models (Kozlov et al., 2007).

Patients with PWS are characterized as having reduced levels of growth hormone, but elevated levels of ghrelin (Tauber et al., 2019). Ghrelin is the endogenous ligand of growth hormone secretagogue receptor 1a. Ghrelin is peptide produced by the gut with a diversity of physiological effects, including appetite stimulation and lipid accumulation. Subsequent studies have demonstrated that it is actually the acylated form of ghrelin that is elevated in PWS children and young adults, while nonacylated ghrelin levels are indistinguishable from controls (Kuppens et al., 2015). However, while both growth hormone and ghrelin are known to have clear diurnal patterns of secretion, with nocturnal levels being higher than daytime levels in humans, there have been a surprising lack of investigation into the possibility growth hormone abnormalities in PWS may be due to altered diurnal rhythms (Kyung et al., 2004; Stawerska et al., 2020).

Despite orexin neurons being a critical cell type for Snord116 regulation on hormonal regulation from the hypothalamus, loss of Snord116 in other brain regions, such as cerebral cortex, also appear to contribute to the proper expression of core circadian clock regulators such as $\mathrm{Per}$ and Bmal genes (Powell et al., 2013; Coulson et al., 2018a). These findings reinforce the role of Snord116 in establishing multiple aspects of circadian rhythms that are lost upon deletion. Studying Snord116 and identifying its targets can contribute to the development of therapeutic interventions that target sleep and metabolism which are critical to development.

\section{PWS Mouse Models for Preclinical Testing of Therapeutic Interventions}

Mouse models of Snord116 deficiency that recapitulate some features of PWS have been created as useful models for testing possible therapeutic interventions. Like in humans, Snord116 is a maternally imprinted gene in mouse and localizes to a syntenic loci chromosome $7 \mathrm{qC}$. The first generation of mouse models generated were designed with large deletions mimicking those observed in humans with PWS (Yang et al., 1998). These mouse models exhibited extreme hypotonia and failure to thrive, leading to death 1 week after birth. The high lethality rate was caused by the loss of protein coding genes Snrpn and Ube3a-ats, which are hypothesized to be important to alternative splicing (Tsai et al., 1999; Bressler et al., 2001; Bervini and Herzog, 2013). As in humans with PWS, these mouse models exhibited a dysregulation of major endocrine hormones including growth hormone, glucose, and insulin, which are necessary for cellular homeostasis and proliferation. Disruption of each hormone lead to metabolic dysregulation which results in extreme hypotonia that leads to the failure to thrive.

Today, the most commonly used PWS mouse models were originally generated by two separate labs using cre-mediated deletion of Snord116 (Skryabin et al., 2007; Ding et al., 2008). These mouse models were designed by a targeted insertion of loxP cassettes flanking the Snord116 (Ding et al., 2008) cluster or Snord116 and IPW (Skryabin et al., 2007) through homologous recombination in embryonic stem (ES) cells derived from male blastocytes. The 2-loxP ES cells were then injected into $\mathrm{C} 57 \mathrm{Bl} / 6 \mathrm{~J}$ mice that gave birth to male mice with a 2-loxP (+/-) genotype. These mice were mated with a transgenic strain expressing Cre recombinase under an ovary specific promoter producing 1-loxP mice with a Snord116 $(+/-)$ genotype (Ding et al., 2008). For ES cells targeted with loxP cassettes flanking Snord116 and IPW, CRE recombinase were expressed then injected into blastocytes to produce PWScre(+/-) (Skryabin et al., 2007). These mouse models have a $150 \mathrm{~kb}$ deletion of the Snord116 cluster or a deletion that encompasses Snord116 and IPW. Like previous models, both mice develop hypotonia and failure to thrive with low to no post-natal lethality. Although these mouse models do not consistently exhibit the hyperphagia phenotype, they do exhibit a significant deficiency in cognition and energy expenditure (Powell et al., 2013; Adhikari et al., 2019) making these phenotypes useful in preclinical therapeutic strategies. Furthermore, development of $2-\operatorname{loxp}(-/+)$ and PWScre $(+/-)$ mice enabled the generation of several new mouse models that are able to recapitulate the hyperphagia phenotype in adult mice through Cre-mediated and tamoxifen induced Snord116 deletion in the hypothalamus (Qi et al., 2016; Purtell et al., 2017; Polex-Wolf et al., 2018) and identified the disrupted REM sleep phenotypes (Lassi et al., 2016b), respectively. Previous studies have shown that Snord116 expression in the 
hypothalamus is developmentally regulated and is enriched postnatally at weaning and early adulthood (Zhang et al., 2012), implicating its involvement in regulating metabolism and circadian rhythms.

\section{Genetic Therapies}

While most genetic diseases are amenable to genetic complementation and standard gene therapy design and delivery, there are unique challenges to gene therapy in PWS because of the epigenetic and molecular complexities of the SNORD116 locus. In the original characterization of a Snord116 deletion mouse model of PWS, it was mentioned that a transgene containing a single snoRNA from Snord116 was insufficient to rescue the metabolic phenotypes (Ding et al., 2008). Since it remained possible that the limitations of using either a single copy and/or an already processed snoRNA were the reason for the lack of complementation, a new transgenic mouse was created and reported by our group using the Snord (+/-) model (Coulson et al., 2018a). This Snord116 transgene contained the complete subunits of $116 \mathrm{HG}$ exons, introns, and snoRNAs repeated in a total of 27 copies was expressed broadly at the transcript level in all tissues, but was only spliced and processed into snoRNAs in brain. The neuron-specific splicing was attributed to the splicing factor RBFOX3, which is also known as the neuron-specific marker NeuN. In wild-type neurons, the extra copies of Snord116 contributed to the nucleolar accumulation of processed snoRNAs as well as the size of the $116 \mathrm{HG}$ RNA cloud. However, in the Snord116 deletion PWS model, the Snord116 transgene did not become processed or localized to these locations, indicating that an active allele was needed for correct processing and localization. In addition, the body weight phenotype of the Snord116 mice was similar to that of the Snord116 deletion mouse, and there was no complementation of this phenotype in the cross.

In another study, a mouse model was generated with a $5^{\prime} H P R T-L o x P-N e o^{\mathrm{R}}$ insertion upstream of the maternally imprinted Snord116 using the PWScre(+/-) model (Rozhdestvensky et al., 2016). The cassette insertion did not affect the PWS imprinting center methylation status, but disrupted the imprinting effect enabling expression of Snord116 from the maternal allele, a result that was not observed in WT and KO mice without the cassette. Like the Coulson et al. study in 2018, Snord116 was expressed across all tissue types, but in this case, the body weight phenotype was rescued in KO mice with the cassette insertion. The differences in results may depend on the imprinting mechanism of the PWS region as well as the genomic location of Snord116. For instance, when the Snord116 transgene is introduced outside of the imprinted region, as would be the case for most gene therapy strategies, the ability to complement the missing paternal allele is expected to be challenging. These results demonstrate the complexities of this locus and suggest that gene therapy for PWS using conventional complementation strategies will be problematic. Despite the issues, these results also highlight the importance of targeting imprinting regulation for therapeutic interventions.

\section{Epigenetic Therapies}

In contrast to gene therapy, epigenetic therapy for PWS has a stronger potential for clinical relevance, since PWS is an inherently epigenetic disorder. The general strategy for epigenetic strategies for PWS involves de-repressing the maternal silent PWS-ICR to activate SNRPN and Snord116 transcription (Crunkhorn, 2017; Chung et al., 2020). Recent successes using high throughput screening of small molecule libraries identified several inhibitors of EHMT2/G9a, a histone 3 lysine 9 methyltransferase, that were capable of reactivating the expression of paternally expressed SNRPN and SNORD116 from the maternal chromosome, both in cultured PWS cell lines and in a PWS mouse model (Kim et al., 2017, 2019). Similarly, inhibitor of SETDB1 using shRNA knockdown resulted in partial reactivation of SNORD116 and $116 \mathrm{HG}$ in PWS-derived iPSC cell lines and neurons (Cruvinel et al., 2014). The main differences in the epigenetic changes resulting between these two epigenetic therapies was that EHMT2/ G9a did not alter DNA methylation at the PWS-ICR, while SETDB1 did not show a change in H3K9me3 at the PWS-ICR. Potentially more completely, the inactivation of ZNF274 using CRISPR/Cas9 in PWS-derived iPSC lines resulted in reactivation of both SNRPN and SNORD116 as well as a reduction of H3K9me3 at the PWS-ICR (Langouët et al., 2020). Together, these studies suggest that combinations of targeted epigenetic strategies for unsilencing maternal SNORD116 hold promise for future treatments of PWS.

\section{POTENTIAL DEVELOPMENTS: RELEVANCE OF SNORD116-MEDIATED EPIGENETIC MECHANISMS TOWARD COMMON HUMAN DISEASES}

While this review has focused on the relevance of epigenetic regulation of and by SNORD116 and other genes within the locus to the pathogenesis of PWS, we expect that understanding the interactions between imprinted genes and metabolism at this locus will have relevance to other more common metabolic and neuropsychiatric human disorders. Because of the hypothalamic network alterations in PWS associated with satiety and food reward systems, this locus is considered to be a model for understanding food addictions as well as other addictive behaviors (Salles et al., 2020). The molecular mechanisms leading hyperphagia and overeating in PWS could be informative for understanding the intersections of epigenetics, diurnal rhythms, and metabolism in more common causes of overweight and obesity. Food addictions in PWS may be similar in mechanisms to those establishing other addictions. Interestingly, "morphine addiction" and "circadian entrainment" were among the gene pathway terms identified by the unbiased search for gene promoters that showed both rhythmic demethylation and increased expression during sleep in Snord116 deletion mice (Coulson et al., 2018a), suggesting that further characterization of these pathways could be relevant to improved treatments for opioid use disorders. In addition, there are emerging links between circadian disruptions 
and the exacerbation of psychiatric disorders such as bipolar disorder and depression. Chronotherapy involving sleep deprivation followed by the re-entrainment of diurnal cycles has shown effectiveness in treating these common mood disorders (Gottlieb et al., 2019; D’Agostino et al., 2020).

In conclusion, the PWS locus epigenetically regulated SNORD116 transcripts that have evolved to become parentally imprinted within mammals, in turn serve to regulate a large number of additional genes through the genome that are related to circadian rhythms, metabolic and nutritional cycles, and brain functions. Future studies designed to better understand the genomic impacts of SNORD116 regulation is expected to have far-reaching impacts beyond the scope of PWS.

\section{REFERENCES}

Adhikari, A., Copping, N. A., Onaga, B., Pride, M. C., Coulson, R. L., Yang, M., et al. (2019). Cognitive deficits in the Snord116 deletion mouse model for Prader-Willi syndrome. Neurobiol. Learn. Mem. 165:106874. doi: 10.1016/j. nlm.2018.05.011

Angulo, M. A., Butler, M. G., and Cataletto, M. E. (2015). Prader-Willi syndrome: a review of clinical, genetic, and endocrine findings. J. Endocrinol. Investig. 38, 1249-1263. doi: 10.1007/s40618-015-0312-9

Azzi, A., Dallmann, R., Casserly, A., Rehrauer, H., Patrignani, A., Maier, B., et al. (2014). Circadian behavior is light-reprogrammed by plastic DNA methylation. Nat. Neurosci. 17, 377-382. doi: 10.1038/nn.3651

Bazeley, P. S., Shepelev, V., Talebizadeh, Z., Butler, M. G., Fedorova, L., Filatov, V., et al. (2008). SnoTARGET shows that human orphan SnoRNA targets locate close to alternative splice junctions. Gene 408, 172-179. doi: 10.1016/j. gene.2007.10.037

Bervini, S., and Herzog, H. (2013). Mouse models of Prader-Willi syndrome: a systematic review. Front. Neuroendocrinol. 34, 107-119. doi: 10.1016/j. yfrne.2013.01.002

Beygo, J., Grosser, C., Kaya, S., Mertel, C., Buiting, K., and Horsthemke, B. (2020). Common genetic variation in the Angelman syndrome imprinting centre affects the imprinting of chromosome 15. Eur. J. Hum. Genet. 28, 835-839. doi: 10.1038/s41431-020-0595-y

Bieth, E., Eddiry, S., Gaston, V., Lorenzini, F., Buffet, A., Auriol, F. C., et al. (2015). Highly restricted deletion of the SNORD116 region is implicated in Prader-Willi syndrome. Eur. J. Hum. Genet. 23, 252-255. doi: 10.1038/ ejhg.2014.103

Blasiak, A., Gundlach, A. L., Hess, G., and Lewandowski, M. H. (2017). Interactions of circadian rhythmicity, stress and orexigenic neuropeptide systems: implications for food intake control. Front. Neurosci. 11:127. doi: $10.3389 /$ fnins.2017.00127

Bortolin-Cavaillé, M. L., and Cavaillé, J. (2012). The SNORD115 (H/MBII-52) and SNORD116 (H/MBII-85) gene clusters at the imprinted Prader-Willi locus generate canonical box C/D SnoRNAs. Nucleic Acids Res. 40, 6800-6807. doi: $10.1093 /$ nar/gks321

Braat, S., and Kooy, R. F. (2015). The GABAA receptor as a therapeutic target for neurodevelopmental disorders. Neuron 86, 1119-1130. doi: 10.1016/j. neuron.2015.03.042

Brancaccio, M., Patton, A. P., Chesham, J. E., Maywood, E. S., and Hastings, M. H. (2017). Astrocytes control circadian timekeeping in the suprachiasmatic nucleus via glutamatergic signaling. Neuron 93, 1420-1435. doi: 10.1016/j. neuron.2017.02.030

Bratkovič, T., Bozič, J., and Rogelj, B. (2020). Functional diversity of small nucleolar RNAs. Nucleic Acids Res. 48, 1627-1651. doi: 10.1093/nar/gkz1140

Bressler, J., Tsai, T. F., Wu, M. Y., Tsai, S. F., Ramirez, M. A., Armstrong, D., et al. (2001). The SNRPN promoter is not required for genomic imprinting of the Prader-Willi/Angelman domain in mice. Nat. Genet. 28, 232-240. doi: $10.1038 / 90067$

Briggs, T. A., Lokulo-Sodipe, K., Chandler, K. E., Mackay, D. J. G., and Karen Temple, I. (2016). Temple syndrome as a result of isolated hypomethylation

\section{AUTHOR CONTRIBUTIONS}

Both authors contributed to the literature review, writing, and editing of the manuscript. All authors contributed to the article and approved the submitted version.

\section{ACKNOWLEDGMENTS}

We are grateful for the support of research on epigenetics in Prader-Willi syndrome from the NIH/NICHD (R01HD098038) and the Foundation for Prader-Willi Research. We would like to thank the home department of Medical Microbiology and Immunology for covering open access fees for this publication.

of the 14q32 imprinted DLK1/MEG3 region. Am. J. Med. Genet. A 170A, 170-175. doi: 10.1002/ajmg.a.37400

Buiting, K., Saitoh, S., Gross, S., Dittrich, B., Schwartz, S., Nicholls, R. D. et al. (1995). Inherited microdeletions in the Angelman and Prader-Willi syndromes define an imprinting centre on human chromosome 15. Nat. Genet. 9, 395-400. doi: 10.1038/ng0495-395

Butler, M. G. (2020). Imprinting disorders in humans: a review. Curr. Opin. Pediatr. 32, 719-729. doi: 10.1097/MOP.0000000000000965

Butler, M. G., Bittel, D. C., Kibiryeva, N., Talebizadeh, Z., and Thompson, T. (2004). Behavioral differences among subjects with Prader-Willi syndrome and type I or type II deletion and maternal disomy. Pediatrics 113, 565-573. doi: 10.1542/peds.113.3.565

Butler, M. G., Hartin, S. N., Hossain, W. A., Manzardo, A. M., Kimonis, V., Dykens, E., et al. (2019a). Molecular genetic classification in Prader-Willi syndrome: a multisite cohort study. J. Med. Genet. 56, 149-153. doi: 10.1136/ jmedgenet-2018-105301

Butler, M. G., Miller, J. L., and Forster, J. L. (2019b). Prader-Willi syndromeclinical genetics, diagnosis and treatment approaches: an update. Curr. Pediatr. Rev. 15, 207-244. doi: 10.2174/1573396315666190716120925

Butler, J. V., Whittington, J. E., Holland, A. J., Boer, H., Clarke, D., and Webb, T. (2002). Prevalence of, and risk factors for, physical ill-health in people with Prader-Willi syndrome: a population-based study. Dev. Med. Child Neurol. 44, 248-255. doi: 10.1017/S001216220100202X

Cassidy, S. B., and Driscoll, D. J. (2009). Prader-Willi syndrome. Eur. J. Hum. Genet. 17, 3-13. doi: 10.1038/ejhg.2008.165

Cassidy, S. B., Schwartz, S., Miller, J. L., and Driscoll, D. J. (2012). Prader-Willi syndrome. Genet. Med. 14, 10-26. doi: 10.1038/gim.0b013e31822bead0

Cavaillé, J., Buiting, K., Kiefmann, M., Lalande, M., Brannan, C. I., Horsthemke, B., et al. (2000). Identification of brain-specific and imprinted small nucleolar RNA genes exhibiting an unusual genomic organization. Proc. Natl. Acad. Sci. U. S. A. 97, 14311-14316. doi: 10.1073/pnas.250426397

Cavaillé, J., Seitz, H., Paulsen, M., Ferguson-Smith, A. C., and Bachellerie, J. P. (2002). Identification of tandemly-repeated C/D SnoRNA genes at the imprinted human $14 \mathrm{q} 32$ domain reminiscent of those at the Prader-Willi/ Angelman syndrome region. Hum. Mol. Genet. 11, 1527-1538. doi: 10.1093/ hmg/11.13.1527

Chamberlain, S. J. (2013). RNAs of the human chromosome 15q11-Q13 imprinted region. Wiley Interdiscip. Rev. RNA 4, 155-166. doi: 10.1002/wrna.1150

Chemelli, R. M., Willie, J. T., Sinton, C. M., Elmquist, J. K., Scammell, T., Lee, C., et al. (1999). Narcolepsy in orexin knockout mice: molecular genetics of sleep regulation. Cell 98, 437-451. doi: 10.1016/S0092-8674(00)81973-X

Chung, M. S., Langouët, M., Chamberlain, S. J., and Carmichael, G. G. (2020). Prader-Willi syndrome: reflections on seminal studies and future therapies. Open Biol. 10:200195. doi: 10.1098/rsob.200195

Coulson, R. L., Powell, W. T., Yasui, D. H., Dileep, G., Resnick, J., and LaSalle, J. M. (2018a). Prader-Willi locus Snord116 RNA processing requires an active endogenous allele and neuron-specific splicing by Rbfox3/NeuN. Hum. Mol. Genet. 27, 4051-4060. doi: 10.1093/hmg/ddy296

Coulson, R. L., Yasui, D. H., Dunaway, K. W., Laufer, B. I., Ciernia, A. V., Zhu, Y., et al. (2018b). Snord116-dependent diurnal rhythm of DNA 
methylation in mouse cortex. Nat. Commun. 9:1616. doi: 10.1038/s41467018-03676-0

Crunkhorn, S. (2017). Steps towards epigenetic therapy for PWS. Nat. Rev. Drug Discov. 16:85. doi: 10.1038/nrd.2017.3

Cruvinel, E., Budinetz, T., Germain, N., Chamberlain, S., Lalande, M., and Martins-Taylor, K. (2014). Reactivation of maternal SNORD116 cluster via SETDB1 knockdown in Prader-Willi syndrome IPSCs. Hum. Mol. Genet. 23, 4674-4685. doi: 10.1093/hmg/ddul87

D’Agostino, A., Ferrara, P., Terzoni, S., Ostinelli, E. G., Carrara, C., Prunas, C., et al. (2020). Efficacy of triple chronotherapy in unipolar and bipolar depression: a systematic review of the available evidence. J. Affect. Disord. 276, 297-304. doi: 10.1016/j.jad.2020.07.026

Davies, W., Lynn, P. M. Y., Relkovic, D., and Wilkinson, L. S. (2008). Imprinted genes and neuroendocrine function. Front. Neuroendocrinol. 29, 413-427. doi: 10.1016/j.yfrne.2007.12.001

de los Santos, T., Schweizer, J., Rees, C. A., and Francke, U. (2000). Small evolutionarily conserved RNA, resembling C/D box small nucleolar RNA, is transcribed from PWCR1, a novel imprinted gene in the Prader-Willi deletion region, which is highly expressed in brain. Am. J. Hum. Genet. 67, 1067-1082. doi: 10.1086/303106

de Smith, A. J., Purmann, C., Walters, R. G., Ellis, R. J., Holder, S. E., Van Haelst, M. M., et al. (2009). A deletion of the HBII-85 class of small nucleolar RNAs (SnoRNAs) is associated with hyperphagia, obesity and hypogonadism. Hum. Mol. Genet. 18, 3257-3265. doi: 10.1093/hmg/ ddp 263

Delahanty, R. J., Zhang, Y., Bichell, T. J., Shen, W., Verdier, K., Macdonald, R. L., et al. (2016). Beyond epilepsy and autism: disruption of GABRB3 causes ocular hypopigmentation. Cell Rep. 17, 3115-3124. doi: 10.1016/j.celrep.2016.11.067

Devos, J., Weselake, S. V., and Wevrick, R. (2011). Magel2, a Prader-Willi syndrome candidate gene, modulates the activities of circadian rhythm proteins in cultured cells. J. Circadian Rhythms 9:12. doi: 10.1186/17403391-9-12

Ding, F., Li, H. H., Zhang, S., Solomon, N. M., Camper, S. A., Cohen, P., et al. (2008). SnoRNA Snord116 (Pwcr1/MBll-85) deletion causes growth deficiency and hyperphagia in mice. PLoS One 3:1709. doi: 10.1371/journal. pone.0001709

Duker, A. L., Ballif, B. C., Bawle, E. V., Person, R. E., Mahadevan, S., Alliman, S., et al. (2010). Paternally inherited microdeletion at $15 q 11.2$ confirms a significant role for the SNORD116 C/D box SnoRNA cluster in Prader-Willi syndrome. Eur. J. Hum. Genet. 18, 1196-1201. doi: 10.1038/ejhg.2010.102

Dupuis-Sandoval, F., Poirier, M., and Scott, M. S. (2015). The emerging landscape of small nucleolar RNAs in cell biology. Wiley Interdiscip. Rev. RNA 6, 381-397. doi: 10.1002/wrna.1284

Fauque, P., Ripoche, M. A., Tost, J., Journot, L., Gabory, A., Busato, F., et al. (2010). Modulation of imprinted gene network in placenta results in normal development of in vitro manipulated mouse embryos. Hum. Mol. Genet. 19, 1779-1790. doi: $10.1093 / \mathrm{hmg} / \mathrm{ddq} 059$

Fountain, M., and Schaaf, C. (2016). Prader-Willi syndrome and Schaaf-Yang syndrome: neurodevelopmental diseases intersecting at the MAGEL2 gene. Diseases 4:2. doi: 10.3390/diseases 4010002

Gerhart-Hines, Z., and Lazar, M. A. (2015). Circadian metabolism in the light of evolution. Endocr. Rev. 36, 289-304. doi: 10.1210/er.2015-1007

Gottlieb, J. F., Benedetti, F., Geoffroy, P. A., Henriksen, T. E. G., Lam, R. W., Murray, G., et al. (2019). The chronotherapeutic treatment of bipolar disorders: a systematic review and practice recommendations from the ISBD task force on chronotherapy and chronobiology. Bipolar Disord. 8, 741-773. doi: 10.1111/bdi.12847

Haga, C. L., and Phinney, D. G. (2012). MicroRNAs in the imprinted DLK1DIO3 region repress the epithelial-to-mesenchymal transition by targeting the TWIST1 protein signaling network. J. Biol. Chem. 287, 42695-42707. doi: 10.1074/jbc.M112.387761

Hartley, S. L., MacLean, W. E., Butler, M. G., Zarcone, J., and Thompson, T. (2005). Maladaptive behaviors and risk factors among the genetic subtypes of Prader-Willi syndrome. Am. J. Med. Genet. 136 A, 140-145. doi: 10.1002/ ajmg.a.30771

Hogart, A., Nagarajan, R. P., Patzel, K. A., Yasui, D. H., and LaSalle, J. M. (2007). 15q11-13 GABAA receptor genes are normally biallelically expressed in brain yet are subject to epigenetic dysregulation in autism-spectrum disorders. Hum. Mol. Genet. 16, 691-703. doi: 10.1093/hmg/ddm014
Holm, V. A., Cassidy, S. B., Butler, M. G., Hanchett, J. M., Greenswag, L. R., Whitman, B. Y., et al. (1993). Prader-Willi syndrome: consensus diagnostic criteria. Pediatrics 91, 398-402.

Hosoki, K., Kagami, M., Tanaka, T., Kubota, M., Kurosawa, K., Kato, M., et al. (2009). Maternal uniparental disomy 14 syndrome demonstrates Prader-Willi syndrome-like phenotype. J. Pediatr. 155, 900-903. doi: 10.1016/j.jpeds. 2009.06.045

Jung, Y., and Nolta, J. A. (2016). BMI1 regulation of self-renewal and multipotency in human mesenchymal stem cells. Curr. Stem Cell Res. Ther. 11, 131-140. doi: 10.2174/1574888X1102160107171432

Kagami, M., Kurosawa, K., Miyazaki, O., Ishino, F., Matsuoka, K., and Ogata, T. (2015). Comprehensive clinical studies in 34 patients with molecularly defined UPD(14)pat and related conditions (Kagami-Ogata syndrome). Eur. J. Hum. Genet. 23, 1488-1498. doi: 10.1038/ejhg.2015.13

Kim, Y., Lee, H. M., Xiong, Y., Sciaky, N., Hulbert, S. W., Cao, X., et al. (2017). Targeting the histone methyltransferase G9a activates imprinted genes and improves survival of a mouse model of Prader-Willi syndrome. Nat. Med. 23, 213-222. doi: 10.1038/nm.4257

Kim, S. J., Miller, J. L., Kuipers, P. J., German, J. R., Beaudet, A. L., Sahoo, T., et al. (2012). Unique and atypical deletions in Prader-Willi syndrome reveal distinct phenotypes. Eur. J. Hum. Genet. 20, 283-290. doi: 10.1038/ ejhg.2011.187

Kim, Y., Wang, S. E., and Jiang, Y. -H. (2019). Epigenetic therapy of PraderWilli syndrome. Transl. Res. 205, 105-118. doi: 10.1016/j.trsl.2019.02.012

Kindler, J. M., Lewis, R. D., and Hamrick, M. W. (2015). Skeletal muscle and pediatric bone development. Curr. Opin. Endocrinol. Diabetes Obes. 22, 467-474. doi: 10.1097/MED.0000000000000201

Koike, N., Yoo, S. H., Huang, H. C., Kumar, V., Lee, C., Kim, T. K., et al. (2012). Transcriptional architecture and chromatin landscape of the core circadian clock in mammals. Science 338, 349-354. doi: 10.1126/ science. 1226339

Kozlov, S. V., Bogenpohl, J. W., Howell, M. P., Wevrick, R., Panda, S., Hogenesch, J. B., et al. (2007). The imprinted gene Magel2 regulates normal circadian output. Nat. Genet. 39, 1266-1272. doi: 10.1038/ng2114

Kuppens, R. J., Diène, G., Bakker, N. E., Molinas, C., Faye, S., Nicolino, M., et al. (2015). Elevated ratio of acylated to unacylated ghrelin in children and young adults with Prader-Willi syndrome. Endocrine 50, 633-642. doi: 10.1007/s12020-015-0614-x

Kuwajima, T., Nishimura, I., and Yoshikawa, K. (2006). Necdin promotes GABAergic neuron differentiation in cooperation with Dlx homeodomain proteins. J. Neurosci. 26, 5383-5392. doi: 10.1523/JNEUROSCI.1262-06.2006

Kuwako, K. I., Hosokawa, A., Nishimura, I., Uetsuki, T., Yamada, M., Nada, S., et al. (2005). Disruption of the paternal necdin gene diminishes TrkA signaling for sensory neuron survival. J. Neurosci. 25, 7090-7099. doi: 10.1523/ JNEUROSCI.2083-05.2005

Kyung, H. P., Jin, D. K., Sang, Y. S., Ji, E. L., Si, H. K., Seng, M. S., et al. (2004). Correlation between fasting plasma ghrelin levels and age, body mass index (BMI), BMI percentiles, and 24-hour plasma ghrelin profiles in Prader-Willi syndrome. J. Clin. Endocrinol. Metab. 89, 3885-3889. doi: 10.1210/jc.2003-032137

Labialle, S., Croteau, S., Bélanger, V., McMurray, E. N., Ruan, X., Moussette, S., et al. (2008a). Novel imprinted transcripts from the Dlk1-Gtl2 intergenic region, micol and micolos, show circadian oscillations. Epigenetics 3, 322-329. doi: 10.4161/epi.3.6.7109

Labialle, S., Yang, L., Ruan, X., Villemain, A., Schmidt, J. V., Hernandez, A., et al. (2008b). Coordinated diurnal regulation of genes from the Dlk1-Dio3 imprinted domain: implications for regulation of clusters of non-paralogous genes. Hum. Mol. Genet. 17, 15-26. doi: 10.1093/hmg/ddm281

Landers, M., Bancescu, D. L., Le Meur, E., Rougeulle, C., Glatt-Deeley, H., Brannan, C., et al. (2004). Regulation of the large $(\sim 1000 \mathrm{~kb})$ imprinted murine Ube3a antisense transcript by alternative exons upstream of Snurf/ Snrpn. Nucleic Acids Res. 32, 3480-3492. doi: 10.1093/nar/gkh670

Langouët, M., Gorka, D., Orniacki, C., Dupont-Thibert, C. M., Chung, M. S., Glatt-Deeley, H. R., et al. (2020). Specific ZNF274 binding interference at SNORD116 activates the maternal transcripts in Prader-Willi syndrome neurons. Hum. Mol. Genet. 29, 3285-3295. doi: 10.1093/hmg/ddaa210

Lassi, G., Maggi, S., Balzani, E., Cosentini, I., Garcia-Garcia, C., and Tucci, V. (2016a). Working-for-food behaviors: a preclinical study in Prader-Willi mutant mice. Genetics 204, 1129-1138. doi: 10.1534/genetics.116.192286 
Lassi, G., Priano, L., Maggi, S., Garcia-Garcia, C., Balzani, E., El-Assawy, N., et al. (2016b). Deletion of the Snord116/SNORD116 alters sleep in mice and patients with Prader-Willi syndrome. Sleep 39, 637-644. doi: 10.5665/ sleep. 5542

Legates, T. A., Fernandez, D. C., and Hattar, S. (2014). Light as a central modulator of circadian rhythms, sleep and affect. Nat. Rev. Neurosci. 15, 443-454. doi: 10.1038/nrn3743

Leung, K. N., Vallero, R. O., Dubose, A. J., Resnick, J. L., and Lasalle, J. M. (2009). Imprinting regulates mammalian SnoRNA-encoding chromatin decondensation and neuronal nucleolar size. Hum. Mol. Genet. 18, 4227-4238. doi: $10.1093 / \mathrm{hmg} / \mathrm{ddp} 373$

Lewis, M. W., Brant, J. O., Kramer, J. M., Moss, J. I., Yang, T. P., Hansen, P. J., et al. (2015). Angelman syndrome imprinting center encodes a transcriptional promoter. Proc. Natl. Acad. Sci. U. S. A. 112, 6871-6875. doi: 10.1073/ pnas. 1411261111

Lewis, M. W., Vargas-Franco, D., Morse, D. A., and Resnick, J. L. (2019). A mouse model of Angelman syndrome imprinting defects. Hum. Mol. Genet. 28, 220-229. doi: 10.1093/hmg/ddy345

Lim, A. S. P., Klein, H. U., Yu, L., Chibnik, L. B., Ali, S., Xu, J., et al. (2017). Diurnal and seasonal molecular rhythms in human neocortex and their relation to Alzheimer's disease. Nat. Commun. 8:14931. doi: 10.1038/ ncomms14931

Lim, A. S. P., Srivastava, G. P., Yu, L., Chibnik, L. B., Xu, J., Buchman, A. S., et al. (2014). 24-hour rhythms of DNA methylation and their relation with rhythms of RNA expression in the human dorsolateral prefrontal cortex. PLoS Genet. 10:e1004792. doi: 10.1371/journal.pgen.1004792

Lopez, S. J., Dunaway, K., Saharul Islam, M., Mordaunt, C., Ciernia, A. V., Meguro-Horike, M., et al. (2017). UBE3A-mediated regulation of imprinted genes and epigenome-wide marks in human neurons. Epigenetics 12, 982-990. doi: 10.1080/15592294.2017.1376151

Lovegrove, B. G., Canale, C., Levesque, D., Fluch, G., Řeháková-Petrů, M., and Ruf, T. (2014a). Are tropical small mammals physiologically vulnerable to arrhenius effects and climate change? Physiol. Biochem. Zool. 87, 30-45. doi: $10.1086 / 673313$

Lovegrove, B. G., and Génin, F. (2008). Torpor and hibernation in a basal placental mammal, the Lesser Hedgehog Tenrec Echinops telfairi. J. Comp. Physiol. B, Biochem. Syst. Environ. Physiol. 178, 691-698. doi: 10.1007/ s00360-008-0257-9

Lovegrove, B. G., Lobban, K. D., and Levesque, D. L. (2014b). Mammal survival at the cretaceous-palaeogene boundary: metabolic homeostasis in prolonged tropical hibernation in tenrecs. Proc. R. Soc. B Biol. Sci. 281:20141304. doi: 10.1098/rspb.2014.1304

Lucignani, G., Panzacchi, A., Bosio, L., Moresco, R. M., Ravasi, L., Coppa, I., et al. (2004). GABAA receptor abnormalities in Prader-Willi syndrome assessed with positron emission tomography and [11C] flumazenil. NeuroImage 22, 22-28. doi: 10.1016/j.neuroimage.2003.10.050

MacDonald, H. R., and Wevrick, R. (1997). The necdin gene is deleted in Prader-Willi syndrome and is imprinted in human and mouse. Hum. Mol. Genet. 6, 1873-1878. doi: 10.1093/hmg/6.11.1873

Martinet, C., Monnier, P., Louault, Y., Benard, M., Gabory, A., and Dandolo, L. (2016). H19 controls reactivation of the imprinted gene network during muscle regeneration. Development 143, 962-971. doi: 10.1242/dev.131771

Matarazzo, V., Caccialupi, L., Schaller, F., Shvarev, Y., Kourdougli, N., Bertoni, A., et al. (2017). Necdin shapes serotonergic development and sert activity modulating breathing in a mouse model for Prader-Willi syndrome. elife 6:e32640. doi: 10.7554/eLife.32640

Mercer, R. E., Kwolek, E. M., Bischof, J. M., Van Eede, M., Henkelman, R. M., and Wevrick, R. (2009). Regionally reduced brain volume, altered serotonin neurochemistry, and abnormal behavior in mice null for the circadian rhythm output gene Magel2. Am. J. Med. Genet. B Neuropsychiatr. Genet. 150B, 1085-1099. doi: 10.1002/ajmg.b.30934

Mignot, E., Lammers, G. J., Ripley, B., Okun, M., Nevsimalova, S., Overeem, S., et al. (2002). The role of cerebrospinal fluid hypocretin measurement in the diagnosis of narcolepsy and other hypersomnias. Arch. Neurol. 59, 1553-1562. doi: 10.1001/archneur.59.10.1553

Miller, J. L., Lynn, C. H., Driscoll, D. J. C., Goldstone, A. P., Gold, J. A., Kimonis, V., et al. (2011). Nutritional phases in Prader-Willi syndrome. Am. J. Med. Genet. A 155A, 1040-1049. doi: 10.1002/ajmg.a.33951
Miller, N. L. G., Wevrick, R., and Mellon, P. L. (2009). Necdin, a Prader-Willi syndrome candidate gene, regulates gonadotropin-releasing hormone neurons during development. Hum. Mol. Genet. 18, 248-260. doi: 10.1093/hmg/ddn344

Mohamad, F. H., and Has, A. T. C. (2019). The $\alpha 5$-containing GABA A receptors-a brief summary. J. Mol. Neurosci. 67, 343-351. doi: 10.1007/ s12031-018-1246-4

Monnier, P., Martinet, C., Pontis, J., Stancheva, I., Ait-Si-Ali, S., and Dandolo, L. (2013). H19 LncRNA controls gene expression of the imprinted gene network by recruiting MBD1. Proc. Natl. Acad. Sci. U. S. A. 110, 20693-20698. doi: $10.1073 /$ pnas. 1310201110

Mukherji, A., Kobiita, A., Damara, M., Misra, N., Meziane, H., Champy, M. F., et al. (2015). Shifting eating to the circadian rest phase misaligns the peripheral clocks with the master SCN clock and leads to a metabolic syndrome. Proc. Natl. Acad. Sci. U. S. A. 112, E6691-E6698. doi: 10.1073/pnas.1519807112

Omokawa, M., Ayabe, T., Nagai, T., Imanishi, A., Omokawa, A., Nishino, S., et al. (2016). Decline of CSF orexin (hypocretin) levels in Prader-Willi syndrome. Am. J. Med. Genet. A 170, 1181-1186. doi: 10.1002/ajmg.a.37542

Pace, M., Falappa, M., Freschi, A., Balzani, E., Berteotti, C., Martire, V. L., et al. (2020). Loss of Snord116 impacts lateral hypothalamus, sleep, and food-related behaviors. JCI Insight 5:e137495. doi: 10.1172/jci.insight.137495

Papazyan, R., Zhang, Y., and Lazar, M. A. (2016). Genetic and epigenomic mechanisms of mammalian circadian transcription. Nat. Struct. Mol. Biol. 23, 1045-1052. doi: 10.1038/nsmb.3324

Polex-Wolf, J., Lam, B. Y. H., Larder, R., Tadross, J., Rimmington, D., Bosch, F., et al. (2018). Hypothalamic loss of Snord116 recapitulates the hyperphagia of Prader-Willi syndrome. J. Clin. Investig. 128, 960-969. doi: 10.1172/ JCI97007

Powell, W. T., Coulson, R. L., Crary, F. K., Wong, S. S., Ach, R. A., Peter, T., et al. (2013). A Prader-Willi locus LncRNA cloud modulates diurnal genes and energy expenditure. Hum. Mol. Genet. 22, 4318-4328. doi: 10.1093/ hmg/ddt281

Purtell, L., Qi, Y., Campbell, L., Sainsbury, A., and Herzog, H. (2017). Adultonset deletion of the Prader-Willi syndrome susceptibility gene Snord116 in mice results in reduced feeding and increased fat mass. Transl. Pediatr. 6, 88-97. doi: 10.21037/tp.2017.03.06

Qi, Y., Purtell, L., Fu, M., Lee, N. J., Aepler, J., Zhang, L., et al. (2016). Snord116 is critical in the regulation of food intake and body weight. Sci. Rep. 6:18614. doi: 10.1038/srep18614

Raabe, C. A., Voss, R., Kummerfeld, D. M., Brosius, J., Galiveti, C. R., Wolters, A., et al. (2019). Ectopic expression of Snord115 in choroid plexus interferes with editing but not splicing of $5-\mathrm{Ht} 2 \mathrm{c}$ receptor pre-MRNA in mice. Sci. Rep. 9, 1-9. doi: 10.1038/s41598-019-39940-6

Rapkins, R. W., Hore, T., Smithwick, M., Ager, E., Pask, A. J., Renfree, M. B., et al. (2006). Recent assembly of an imprinted domain from non-imprinted components. PLoS Genet. 2:e182. doi: 10.1371/journal.pgen.0020182

Relkovic, D., and Isles, A. R. (2013). Behavioural and cognitive profiles of mouse models for Prader-Willi syndrome. Brain Res. Bull. 92, 41-48. doi: 10.1016/j.brainresbull.2011.09.009

Ren, J., Lee, S., Pagliardini, S., Gérard, M., Stewart, C. L., Greer, J. J., et al. (2003). Absence of Ndn, encoding the Prader-Willi syndrome-deleted gene necdin, results in congenital deficiency of central respiratory drive in neonatal mice. J. Neurosci. 23, 1569-1573. doi: 10.1523/JNEUROSCI.23-05-01569.2003

Ribarska, T., Goering, W., Droop, J., Bastian, K. M., Ingenwerth, M., and Schulz, W. A. (2014). Deregulation of an imprinted gene network in prostate cancer. Epigenetics 9, 704-717. doi: 10.4161/epi.28006

Rice, L. J., Lagopoulos, J., Brammer, M., and Einfeld, S. L. (2016). Reduced gamma-aminobutyric acid is associated with emotional and behavioral problems in Prader-Willi syndrome. Am. J. Med. Genet. B Neuropsychiatr. Genet. 171, 1041-1048. doi: 10.1002/ajmg.b.32472

Rittinger, O. (2001). Clinical features and genetic analysis of Prader-Willi syndrome. Klinische Padiatrie 4, 387-392. doi: 10.1055/s-2001-15857.

Rozhdestvensky, T. S., Robeck, T., Galiveti, C. R., Raabe, C. A., Seeger, B., Wolters, A., et al. (2016). Maternal transcription of non-protein coding RNAs from the PWS-critical region rescues growth retardation in mice. Sci. Rep. 6, 1-10. doi: 10.1038/srep20398

Runte, M., Hüttenhofer, A., Groß, S., Kiefmann, M., Horsthemke, B., and Buiting, K. (2001). The IC-SNURF-SNRPN transcript serves as a host for multiple small nucleolar RNA species and as an antisense RNA for UBE3A. Hum. Mol. Genet. 10, 2687-2700. doi: 10.1093/hmg/10.23.2687 
Runte, M., Varon, R., Horn, D., Horsthemke, B., and Buiting, K. (2005). Exclusion of the C/D box SnoRNA gene cluster HBII-52 from a major role in PraderWilli syndrome. Hum. Genet. 116, 228-230. doi: 10.1007/s00439-004-1219-2

Sahoo, T., del Gaudio, D., German, J. R., Shinawi, M., Peters, S. U., Person, R. E., et al. 2008. "Prader-Willi phenotype caused by paternal deficiency for the HBII-85 C/D box small nucleolar RNA cluster." Nat. Genet. 40, 719-721. doi: $10.1038 / \mathrm{ng} .158$

Salles, J., Lacassagne, E., Eddiry, S., Franchitto, N., Salles, J. -P., and Tauber, M. (2020). What can we learn from PWS and SNORD116 genes about the pathophysiology of addictive disorders? Mol. Psychiatry 26, 51-59. doi: 10.1038/s41380-020-00917-x

Samaco, R. C., Hogart, A., and LaSalle, J. M. (2005). Epigenetic overlap in autism-spectrum neurodevelopmental disorders: MECP2 deficiency causes reduced expression of UBE3A and GABRB3. Hum. Mol. Genet. 14, 483-492. doi: $10.1093 / \mathrm{hmg} / \mathrm{ddi} 045$

Schaaf, C. P., Gonzalez-Garay, M. L., Xia, F., Potocki, L., Gripp, K. W., Zhang, B., et al. (2013). Truncating mutations of MAGEL2 cause Prader-Willi phenotypes and autism. Nat. Genet. 45, 1405-1408. doi: 10.1038/ng.2776

Schanen, N. C. (2006). Epigenetics of autism spectrum disorders. Hum. Mol. Genet. 15(Suppl. 2), R138-R150. doi: 10.1093/hmg/ddl213

Scoles, H. A., Urraca, N., Chadwick, S. W., Reiter, L. T., and Lasalle, J. M. (2011). Increased copy number for methylated maternal $15 \mathrm{q}$ duplications leads to changes in gene and protein expression in human cortical samples. Mol. Autism. 2:19. doi: 10.1186/2040-2392-2-19

Siegel, J. M. (2005). Clues to the functions of mammalian sleep. Nature 437, 1264-1271. doi: 10.1038/nature04285

Skryabin, B. V., Gubar, L. V., Seeger, B., Pfeiffer, J., Handel, S., Robeck, T., et al. (2007). Deletion of the MBII-85 SnoRNA gene cluster in mice results in postnatal growth retardation." Edited by A. C. Ferguson-Smith. PLoS Genet. 3:e235. doi: 10.1371/journal.pgen.0030235

Smith, E. Y., Futtner, C. R., Chamberlain, S. J., Johnstone, K. A., and Resnick, J. L. (2011). Transcription is required to establish maternal imprinting at the Prader-Willi syndrome and Angelman syndrome locus. PLoS Genet. 7:e1002422. doi: 10.1371/journal.pgen.1002422

Stanurova, J., Neureiter, A., Hiber, M., de Oliveira Kessler, H., Stolp, K., Goetzke, R., et al. (2018). Corrigendum: angelman syndrome-derived neurons display late onset of paternal UBE3A silencing. Sci. Rep. 8:46952. doi: 10.1038/ srep46952

Stawerska, R., Kolasa-Kicińska, M., Łupińska, A., Hilczer, M., and Lewiński, A. (2020). Comparison of nocturnal and morning ghrelin concentration in children with growth hormone deficiency and with idiopathic short stature. Chronobiol. Int. 37, 1629-1635. doi: 10.1080/07420528.2020.1797765

Stelzer, Y., Sagi, I., Yanuka, O., Eiges, R., and Benvenisty, N. (2014). The noncoding RNA IPW regulates the imprinted DLK1-DIO3 locus in an induced pluripotent stem cell model of Prader-Willi syndrome. Nat. Genet. 46, 551-557. doi: 10.1038/ng.2968

Stevenson, T. J., and Prendergast, B. J. (2013). Reversible DNA methylation regulates seasonal photoperiodic time measurement. Proc. Natl. Acad. Sci. U. S. A. 110, 16651-16656. doi: 10.1073/pnas.1310643110

Sutcliffe, J. S., Nakao, M., Christian, S., Örstavik, K. H., Tommerup, N., Ledbetter, D. H., et al. (1994). Deletions of a differentially methylated CpG island at the SNRPN gene define a putative imprinting control region. Nat. Genet. 8, 52-58. doi: 10.1038/ng0994-52

Tacer, K. F., and Potts, P. R. (2017). Cellular and disease functions of the Prader-Willi syndrome gene Magel2. Biochem. J. 474, 2177-2190. doi: 10.1042/ BCJ20160616

Takahashi, J. S. (2017). Transcriptional architecture of the mammalian circadian clock. Nat. Rev. Genet. 18, 164-179. doi: 10.1038/nrg.2016.150

Tauber, M., Coupaye, M., Diene, G., Molinas, C., Valette, M., and Beauloye, V. (2019). Prader-Willi syndrome: a model for understanding the ghrelin system. J. Neuroendocrinol. 31:e12728. doi: 10.1111/jne.12728

Temple, I. K., Cockwell, A., Hassold, T., Pettay, D., and Jacobs, P. (1991). Maternal uniparental disomy for chromosome 14. J. Med. Genet. 8, 131-138. doi: 10.1136/jmg.28.8.511

Tennese, A. A., and Wevrick, R. (2011). Impaired hypothalamic regulation of endocrine function and delayed counterregulatory response to hypoglycemia in Magel2-null mice. Endocrinology 152, 967-978. doi: 10.1210/en.2010-0709

Tierling, S., Dalbert, S., Schoppenhorst, S., Tsai, C. E., Oliger, S., Ferguson-Smith, A. C., et al. (2006). High-resolution map and imprinting analysis of the gtl2-dnchc1 domain on mouse chromosome 12. Genomics 87, 225-235. doi: 10.1016/j.ygeno.2005.09.018

Torrado, M., Araoz, V., Baialardo, E., Abraldes, K., Mazza, C., Krochik, G., et al. (2007). Clinical-etiologic correlation in children with Prader-Willi syndrome (PWS): an interdisciplinary study. Am. J. Med. Genet. A 143, 460-468. doi: 10.1002/ajmg.a.31520

Tsai, T. F., Jiang, Y. H., Bressler, J., Armstrong, D., and Beaudet, A. L. (1999). Paternal deletion from Snrpn to Ube3a in the mouse causes hypotonia, growth retardation and partial lethality and provides evidence for a gene contributing to Prader-Willi syndrome. Hum. Mol. Genet. 8, 1357-1364. doi: 10.1093/hmg/8.8.1357

Vanessa Carias, K., Zoeteman, M., Seewald, A., Sanderson, M. R., Bischof, J. M., and Wevrick, R. (2020). A MAGEL2-deubiquitinase complex modulates the ubiquitination of circadian rhythm protein CRY1. PLoS One 15:e0230874. doi: 10.1371/journal.pone.0230874

Vgontzas, A. N., Bixler, E. O., Kales, A., Centurione, A., Rogan, P. K., Mascari, M., et al. (1996). Daytime Sleepines and rem abrormalities in Prader-Willi syndrome: evidence of generalized hypoarousal. Int. J. Neurosci. 87, 127-139. doi: 10.3109/00207459609070832

Vincent, R. N., Gooding, L. D., Louie, K., Wong, E. C., and Ma, S. (2016). Altered DNA methylation and expression of PLAGL1 in cord blood from assisted reproductive technology pregnancies compared with natural conceptions. Fertil. Steril. 106, 739.e3-748.e3. doi: 10.1016/j.fertnstert.2016.04.036

Vitali, P., Royo, H., Marty, V., Bortolin-Cavaillé, M. L., and Cavaillé, J. (2010). Long nuclear-retained non-coding RNAs and allele-specific higher-order chromatin organization at imprinted SnoRNA gene arrays. J. Cell Sci. 123, 70-83. doi: $10.1242 /$ jcs.054957

Winter, J. (2015). Micrornas of the Mir379-410 cluster: new players in embryonic neurogenesis and regulators of neuronal function. Neurogenesis 2:e1004970. doi: 10.1080/23262133.2015.1004970

Wright, K. P., McHill, A. W., Birks, B. R., Griffin, B. R., Rusterholz, T., and Chinoy, E. D. (2013). Entrainment of the human circadian clock to the natural light-dark cycle. Curr. Biol. 23, 1554-1558. doi: 10.1016/j.cub.2013.06.039

Wu, H., Ng, C., Villegas, V., Chamberlain, S., Cacace, A., and Wallace, O. (2019). Small molecule inhibitors of G9a reactivate the maternal PWS genes in Prader-Willi-syndrome patient derived neural stem cells and differentiated neurons. BioRxiv [preprint server]. doi: 10.1101/640938

Yan, J., Wang, H., Liu, Y., and Shao, C. (2008). Analysis of gene regulatory networks in the mammalian circadian rhythm. PLoS Comput. Biol. 4:e1000193. doi: 10.1371/journal.pcbi.1000193

Yang, T., Adamson, T. E., Resnick, J. L., Leff, S., Wevrick, R., Francke, U., et al. (1998). A mouse model for Prader-Willi syndrome imprinting-centre mutations. Nat. Genet. 19, 25-31. doi: 10.1038/ng0598-25

Yasui, D. H., Scoles, H. A., Horike, S. -I., Meguro-Horike, M., Dunaway, K. W., Schroeder, D. I., et al. (2011). 15q11.2-13.3 chromatin analysis reveals epigenetic regulation of CHRNA7 with deficiencies in rett and autism brain. Hum. Mol. Genet. 20, 4311-4323. doi: 10.1093/hmg/ddr357

Zhang, Q., Bouma, G. J., McClellan, K., and Tobet, S. (2012). Hypothalamic expression of SnoRNA Snord116 is consistent with a link to the hyperphagia and obesity symptoms of Prader-Willi syndrome. Int. J. Dev. Neurosci. 30, 479-478. doi: 10.1016/j.ijdevneu.2012.05.005

Zhang, R., Lahens, N. F., Ballance, H. I., Hughes, M. E., and Hogenesch, J. B. (2014). A circadian gene expression atlas in mammals: implications for biology and medicine. Proc. Natl. Acad. Sci. U. S. A. 111, 16219-16224. doi: 10.1073/pnas.1408886111

Zhang, Y. J., Yang, J. H., Shi, Q. S., Zheng, L. L., Liu, J., Zhou, H., et al. (2014). Rapid birth-and-death evolution of imprinted SnoRNAs in the Prader-Willi syndrome locus: implications for neural development in euarchontoglires. PLoS One 9:e100329. doi: 10.1371/journal.pone.0100329

Conflict of Interest: The authors declare that the research was conducted in the absence of any commercial or financial relationships that could be construed as a potential conflict of interest.

Copyright (c) 2021 Mendiola and LaSalle. This is an open-access article distributed under the terms of the Creative Commons Attribution License (CC BY). The use, distribution or reproduction in other forums is permitted, provided the original author(s) and the copyright owner(s) are credited and that the original publication in this journal is cited, in accordance with accepted academic practice. No use, distribution or reproduction is permitted which does not comply with these terms. 